\title{
Growth and scintillation properties of
}

praseodymium doped

\section{$(\mathrm{Lu}, \mathrm{Gd})_{3}(\mathrm{Ga}, \mathrm{Al})_{5} \mathrm{O}_{12}$ single crystals}

$\underline{\text { Kei Kamada }}^{1,2}$, Martin Nikl ${ }^{3}$, Shunsuke Kurosawa ${ }^{1,4}$, Yasuhiro Shoji ${ }^{2,4}$, Jan Pejchal $^{1,3}$, Yuji Ohashi ${ }^{4}$, Yuui Yokota ${ }^{1}$, and Akira Yoshikawa ${ }^{1,2,4}$

\section{${ }^{1}$ Tohoku University}

New Industry Creation Hatchery Center, 6-6-10 Aoba, Aramaki, Aoba-ku, Sendai, Miyagi, 980-8579, Japan

${ }^{2}$ C\&A corporation

T-Biz, 6-6-10 Aoba, Aramaki, Aoba-ku, Sendai, Miyagi 980-8579, Japan

${ }^{3}$ Institute of Physics AS CR, Cukrovarnicka 10, 16253 Prague, Czech Republic

${ }^{4}$ Tohoku University

Institute for Material Reseach, 2-1-1 Katahira Aoba-ku, Sendai, Miyagi, 980-8577, Japan 


\begin{abstract}
Pr doped $(\mathrm{Lu}, \mathrm{Gd})_{3}(\mathrm{Ga}, \mathrm{Al})_{5} \mathrm{O}_{12}$ single crystals were grown by the micro-pulling down ( $\mu$-PD) method. The crystals were greenish and transparent with $3.0 \mathrm{~mm}$ in diameter, 10-30 $\mathrm{mm}$ in length. Neither visible inclusions nor cracks were observed. Luminescence and scintillation properties were measured. The substitution at the $\mathrm{Al}^{3+}$ sites by $\mathrm{Ga}^{3+}$ in garnet structure has been studied. The $\operatorname{Pr}^{3+} 5 \mathrm{~d}-4 \mathrm{f}$ emission is observed within $300-380 \mathrm{~nm}$ wavelength superposed with $312 \mathrm{~nm}$ emission line of $\mathrm{Gd}^{3+}$. Pr0.2\%: $\mathrm{Lu}_{2.5} \mathrm{Gd}_{1} \mathrm{Ga}_{3} \mathrm{Al}_{2} \mathrm{O}_{12}$ shows highest emission intensity. The light yield of $\operatorname{Pr} 0.2 \%: \mathrm{Lu}_{2.5} \mathrm{Gd}_{0.5} \mathrm{Ga}_{2} \mathrm{Al}_{3} \mathrm{O}_{12}$ sample with diameter $3 \mathrm{~mm} \mathrm{x} 1 \mathrm{~mm}$ size was around $8,000 \mathrm{ph} / \mathrm{MeV}$. Two-exponential approximation of scintillation decay showed $39.6 \mathrm{~ns}(30.6 \%)$ and $151 \mathrm{~ns}(69.4 \%)$ decay times.
\end{abstract}




\section{Introduction}

Single crystal scintillator materials are widely used for detection of high-energy photons and particles, in medical imaging techniques, high energy and nuclear physics detectors, high-tech industrial applications. Recently developed Ce-activated materials show the best Fig.-of-merit given by a combination of stopping power, speed, and light yield [1-3]. The latest generation of $\mathrm{Ce}^{3+}$-doped scintillators based on aluminum garnets (LuAG:Ce) show high intrinsic scintillation efficiency and light yield up to $26,000 \mathrm{ph} / \mathrm{MeV}$ [4,5]. However, their performance is always negatively influenced by shallow electron traps which delay an energy transfer to $\mathrm{Ce}^{3+}$ emission centers and scintillation decay time contains a considerable amount of slow components [6]. After systematic study of $\mathrm{Lu}_{3} \mathrm{Al}_{5} \mathrm{O}_{12}$-based single crystal scintillators[7], a new material concept was proposed, based on single crystal multicomponent $(\mathrm{Gd}, \mathrm{RE})_{3}(\mathrm{Ga}, \mathrm{Al})_{5} \mathrm{O}_{12}$ host, $\mathrm{RE}=\mathrm{Lu}$, Y. Doped by $\mathrm{Ce}^{3+}$, such a host lattice, with balanced combination of the admixed $\mathrm{Gd}$ and $\mathrm{Ga}$ (called as multicomponent garnets) demonstrated very high light yield exceeding 50,000 ph/MeV both in single crystal and ceramic materials [7-10].

On the other hand, $\mathrm{Pr}^{3+}$ ion also shows the $5 \mathrm{~d}-4 \mathrm{f}$ emission with the fast decay time in several host materials and such systems can be another candidate for high Fig.-of-merit scintillator. Among Pr-doped materials the $\mathrm{Pr}_{\mathrm{Lu}_{3}} \mathrm{Al}_{5} \mathrm{O}_{12}$ (Pr:LuAG) single crystal was found very promising due to the high density $\left(6.7 \mathrm{~g} / \mathrm{cm}^{3}\right)$, high light output (around 20,000 ph/MeV), very good energy resolution (below $5 \%$ \% 662 $\mathrm{keV}$ ) and very fast $\operatorname{Pr}^{3+} 5 \mathrm{~d}-4 \mathrm{f}$ emission decay time $(20 \mathrm{~ns})$ [7,11-14]. Although the optimized compositions of multicomponent garnets mentioned above provided the values of light yield above $50,000 \mathrm{phMeV}$ in the case of $\mathrm{Ce}^{3+}$ doping, the analogous Pr-doped ones show light yield values only up to $4,000-4,500 \mathrm{phMeV} \mathrm{[15],.Such} \mathrm{deterioration} \mathrm{of} \mathrm{scintillation} \mathrm{efficiency} \mathrm{and} \mathrm{light} \mathrm{yield} \mathrm{was} \mathrm{explained}$ by the unwanted energy transfer from $5 \mathrm{~d}_{1}$ excited state of $\mathrm{Pr}^{3+}$ towards $\mathrm{Gd}^{3+}$ and concentration quenching in the Gd-sublattice [16,17]. Composition engineering can, in principle, be a way to set the above mentioned transitions of $\mathrm{Pr}^{3+}$ and $\mathrm{Gd}^{3+}$ off resonance. As a result, an unwanted depletion of $5 \mathrm{~d}_{1}$ $\operatorname{Pr}^{3+}$ excited state would reduce and the light yield of the material would improve.

In this report, the $\operatorname{Pr}(\mathrm{Lu}, \mathrm{Gd})_{3}(\mathrm{Ga}, \mathrm{Al})_{5} \mathrm{O}_{12}$ (Pr:LGGAG) single crystals with different host compositions were grown by the micro-pulling down ( $\mu$-PD) method. Luminescence and scintillation properties were measured. The substitution phenomenon in the $\mathrm{Al}^{3+}$ sites with $\mathrm{Ga}^{3+}$ in garnet structure has been studied.

\section{Experimental}

\subsection{Crystal Growth}


A stoichiometric mixture of $4 \mathrm{~N} \mathrm{Pr}_{6} \mathrm{O}_{11}, \mathrm{Lu}_{2} \mathrm{O}_{3}, \mathrm{Gd}_{2} \mathrm{O}_{3}, \beta-\mathrm{Ga}_{2} \mathrm{O}_{3}$ and $\alpha-\mathrm{Al}_{2} \mathrm{O}_{3}$ powders (High Purity Chemicals Co.) was used as starting material. The $\mathrm{Gd}^{3+}$ site was partially substituted by $\mathrm{Pr}^{3+}$ according to the formula of $\left(\operatorname{Pr}_{\mathrm{z}} \mathrm{Lu}_{\mathrm{y}} \mathrm{Gd}_{1-\mathrm{y}-\mathrm{z}}\right)_{3}\left(\mathrm{Ga}_{\mathrm{x}} \mathrm{Al}_{1-\mathrm{x}}\right)_{5} \mathrm{O}_{12}$. Single crystals of Pr:LGGAG were grown by the $\mu$-PD method with an RF heating system. Parameter y was 0.01 and $3 \mathrm{~mol} \%$ of $\beta-\mathrm{Ga}_{2} \mathrm{O}_{3}$ was added in excess to compensate ignition loss. A schematic layout of the $\mu$-PD growth apparatus is given in Refs. $[18,19]$. Typical pulling rates were $0.05-0.07 \mathrm{~mm} / \mathrm{min}$ and the diameter was around $3 \mathrm{~mm}$. Crystals were grown from an Ir crucible under $\mathrm{N}_{2}$ atmosphere with $1 \%$ of $\mathrm{O}_{2}$ added to prevent evaporation of gallium oxide. The seed crystals were $\langle 111\rangle$ oriented undoped LuAG crystals. Plates of $3 \phi \mathrm{mm} \times 1$ $\mathrm{mm}$ were cut and polished for the purposes of the luminescence and gamma-ray response measurements, while the remaining rods were used for the structure and chemical composition analysis.

\subsection{Structure determination}

Pieces of the grown crystals were crushed and ground into powder in a mortar. Powder X-ray diffraction analysis was carried out in the $2 \theta$ range of $15^{\circ}-75^{\circ}$ using RINT Ultima (RIGAKU) diffractometer. The $\mathrm{CuK} \alpha \mathrm{X}$-ray source was used, the accelerating voltage and current were of $40 \mathrm{kV}$ and $40 \mathrm{~mA}$, respectively.

Quantitative chemical analysis of the grown crystals for the $\mathrm{Al}, \mathrm{Ga}, \mathrm{Pr}$ and $\mathrm{Gd}$ content along the growth direction was performed by electron probe microanalysis (EPMA; JXA-8621MX, JEOL). So called ZAF correction was used, where $\mathrm{Z}$ stands for atomic number, A for absorption correction factor and $\mathrm{F}$ for fluorescence correction factor, respectively.

\subsection{Optical, luminescence and gamma-ray response measurement procedure}

Absorption spectra were measured by the Shimadzu 3101PC spectrometer in the 190-800 nm range. Radioluminescence (RL) spectra and photoluminescence decays at room temperature (RT) were measured at custom made 5000M model of Horiba Jobin Yvon spectrofluorometer using an X-ray tube (operated at $35 \mathrm{kV}$ and $16 \mathrm{~mA}$, Mo cathode) and the pulsed nanosecond hydrogen-filled flashlamp for the excitation, respectively, see [17] for further experimental details.

To determine the light yield, the energy spectra were collected under $662 \mathrm{keV} \gamma$-ray excitation $\left({ }^{137} \mathrm{Cs}\right.$ source) by using a PMT (Hamamatsu H7600, super bialkali photocathode, quartz window). The $3 \phi \mathrm{mm}^{2}$ face of the pieces was coupled with the PMT by using optical grease (OKEN, 6262A). The pieces were covered by using Teflon-tape. The signal was fed into a shaping amplifier (ORTEC 
572A), a multichannel analyzer (MCA) (ORTEC 926), and finally to a personal computer. The shaping time was set as $0.5 \mu$ s. The bias for the PMT was supplied by an ORTEC 556.

\section{Result and discussion}

3.1 Composition and structure properties of as-grown crystals

Pr doped $\mathrm{Lu}_{2} \mathrm{Gd}_{1}\left(\mathrm{Ga}_{\mathrm{y}}, \mathrm{Al}_{1-\mathrm{y}}\right)_{5} \mathrm{O}_{12}$. ( $\mathrm{y}=$ 0, 1, 2, 3, 4 and 5), $\mathrm{Lu}_{1} \mathrm{Gd}_{2}\left(\mathrm{Ga}_{\mathrm{y}}, \mathrm{Al}_{1-\mathrm{y}}\right)_{5} \mathrm{O}_{12}$. ( $\mathrm{y}=$ 0, 1, 2, 3, 4 and 5) and $\mathrm{Lu}_{2.5} \mathrm{Gd}_{0.5}\left(\mathrm{Ga}_{\mathrm{y}}, \mathrm{Al}_{1-\mathrm{y}}\right)_{5} \mathrm{O}_{12}$ crystals were grown by the $\mu$-PD method. Example photos of as-grown crystals are shown in Fig. 1. The grown crystals were transparent with greenish color, 2-3 mm in diameter and 10-30 mm in length. Some of them looked slightly cloudy because of the rough surface caused by gallium oxide evaporation or thermal etching. However, the inner part of all the crystals was perfectly transparent.

Powder X-ray diffraction was performed to identify crystal phase of grown crystals. Selected results of the powder X-ray diffraction of $\operatorname{Pr} 1 \% \mathrm{Lu}_{1} \mathrm{Gd}_{2}\left(\mathrm{Ga}_{\mathrm{x}} \mathrm{Al}_{1-\mathrm{x}}\right)_{5} \mathrm{O}_{12}(\mathrm{x}=1,2,3,4$ and 5) as a function of the $\mathrm{Ga}^{3+}$ concentration are shown in Fig. 2. All of the grown crystals showed the cubic garnet phase. As the $\mathrm{Ga}^{3+}$ concentration increases, the peaks are shifted to the left. The composition distribution in grown crystals was monitored by the EPMA.

The composition distribution for Ga of the grown Pr1\%:LGGAG crystals is shown in Fig. 3-a and for Pr in Fig. 3-b. The cation $\mathrm{Gd}^{3+}$ was distributed almost uniformly along the growth axis. The composition distributions of $\mathrm{Pr}: \mathrm{Lu}_{2} \mathrm{Gd}_{1} \mathrm{Ga}_{2} \mathrm{Al}_{3} \mathrm{O}_{12}$ in radial direction are shown in Fig. 4. According to the previous report [9], segregation coefficients of $\mathrm{Lu}, \mathrm{Ga}$ and $\operatorname{Pr}$ ions were $k_{\text {eff }}>1, k_{\text {eff }}<1$ and $k_{\text {eff }}<1$, respectively, considering the diagnostic distribution curves.

\subsection{Optical and luminescence properties}

Fig. 4 shows absorption spectra of the Pr:LGGAG samples. Pr-doped samples show expected $4 f-5 d_{1,2}$ transitions marked in the Fig. and also the transitions related to $\mathrm{Gd}^{3+}$ are marked. There is strange peak at about $230 \mathrm{~nm}$ in $\operatorname{Pr}_{\mathrm{Gd}_{3}} \mathrm{Ga}_{2} \mathrm{Al}_{3} \mathrm{O}_{12}$ the origin of which is not clear (not related neither to $\mathrm{Gd}^{3+}$ nor to $\mathrm{Pr}^{3+}$ ). Absorption peaks of $\operatorname{Pr}^{3+} 4 \mathrm{f}-5 \mathrm{~d}_{1,2}$ shifted to shorter wavelength with increasing Lu concentration. It is good agreement with our previous report [9].

RL spectra of the as-grown Pr:LGGAG crystals are given in Fig. 5. The expected $312 \mathrm{~nm}$ emission of $\mathrm{Gd}^{3+}$ 4f-4f, 290-420 nm emission of $\operatorname{Pr}^{3+} 4 \mathrm{f}-5 \mathrm{~d}$ and 480-800 nm emission of $\operatorname{Pr}^{3+} 4 \mathrm{f}-4 \mathrm{f}$ transition were observed. In fig.5(a), the highest RL intensity of 5d-4f emission of $\mathrm{Pr}^{3+}$ within 300-400 nm (excluded $312 \mathrm{~nm}$ line of $\mathrm{Gd}^{3+}$ ) is obtained for $\mathrm{Lu}_{2} \mathrm{Gd}_{1} \mathrm{Ga}_{2} \mathrm{Al}_{3} \mathrm{O}_{12}$ composition. Maximum of $5 \mathrm{~d}-4 \mathrm{f}$ emission of $\mathrm{Pr}^{3+}$ is substantially shifted to longer wavelength beyond $350 \mathrm{~nm}$ which may indicate selective depletion of 
radiative transitions from $5 \mathrm{~d}_{1}$ level ending at $3 \mathrm{H}_{4}$ and $3 \mathrm{H}_{5}$ ones which are in resonance with $\mathrm{Gd}^{3+}$ transitions [16,17] For $\operatorname{Pr}: \mathrm{Lu}_{2.5} \mathrm{Gd}_{0.5} \mathrm{Ga}_{2} \mathrm{Al}_{3} \mathrm{O}_{12}$ : the emission maximum shifts to shorter wavelength of about $300 \mathrm{~nm}$ with respect to pure Pr:LuAG (at $308 \mathrm{~nm}$ ) and gets partially out-of-resonance with $\mathrm{Gd}^{3+}$ transitions within 305-310 nm. RL intensity of $\mathrm{Pr}: \mathrm{Lu}_{2.5} \mathrm{Gd}_{0.5} \mathrm{Ga}_{2} \mathrm{Al}_{3} \mathrm{O}_{12}$ shows of about $500 \%$ BGO (fig.5(b))

\subsection{Gamma-ray response}

Fig. 6 shows the energy spectra of the grown Pr: LGGAG samples and a Pr:LuAG standard produced by Furukawa Co. Itd.[20] irradiated by ${ }^{137} \mathrm{Cs}$ (662 keV photons). As shown in Fig. 6, $\operatorname{Pr} 0.2 \%: \mathrm{Lu}_{2.5} \mathrm{Gd}_{0.5} \mathrm{Ga}_{3} \mathrm{Al}_{2} \mathrm{O}_{12}$ sample shows the highest light output which is consistent with its high RL intensity in Fig. 5b. The light output of $\operatorname{Pr} 0.2 \%: \mathrm{Lu}_{2.5} \mathrm{Gd}_{0.5} \mathrm{Ga}_{3} \mathrm{Al}_{2} \mathrm{O}_{12}$ sample was around $40 \%$ of Czochralski (Cz)grown Pr:LuAG standard, of about 8,000 ph/MeV.

Scintillation decay curves were observed by using the PMT and digital oscilloscope TD5032B irradiated by ${ }^{137} \mathrm{Cs}$. Fig. 7 shows decay curve of the $\operatorname{Pr} 0.2 \%: \mathrm{Lu}_{2.5} \mathrm{Gd}_{0.5} \mathrm{Ga}_{2} \mathrm{Al}_{3} \mathrm{O}_{12}$ sample. Two-exponential approximation provided decay time values (component intensities) of $39.6 \mathrm{~ns}$ (30.6\%) and $151 \mathrm{~ns}(69.4 \%)$

\section{Conclusion}

Pr doped LGGAG single crystals were grown by the $\mu$-PD method with RF heating system. The highest RL intensity of 5d-4f emission of $\operatorname{Pr}^{3+}$ within 300-400 nm (excluded $312 \mathrm{~nm}$ line of $\mathrm{Gd}^{3+}$ ) is obtained for $\mathrm{Lu}_{2.5} \mathrm{Gd}_{0.5} \mathrm{Ga}_{2} \mathrm{Al}_{3} \mathrm{O}_{12}$ composition. Maximum of $5 \mathrm{~d}-4 \mathrm{f}$ emission of $\operatorname{Pr}^{3+}$ is substantially shifted to longer wavelength beyond $350 \mathrm{~nm}$ which may indicate the selective depletion of radiative transitions from $5 \mathrm{~d}_{1}$ level ending at $3 \mathrm{H}_{4}$ and $3 \mathrm{H}_{5}$ ground state ones which are in resonance with the $\mathrm{Gd}^{3+}$ absorption transitions. The light output of $\operatorname{Pr} 0.2 \%: \mathrm{Lu}_{2.5} \mathrm{Gd}_{0.5} \mathrm{Ga}_{3} \mathrm{Al}_{2} \mathrm{O}_{12}$ sample was around $40 \%$ of the $\mathrm{Cz}$ grown Pr:LuAG standard and its value was caalculated around 8,000 ph/MeV. Scintillation decay times (component intensities) were evaluated as $39.6 \mathrm{~ns}(30.6 \%)$ and $151 \mathrm{~ns}(69.4 \%)$.

\section{Acknowledgement}

This work is partially supported by (i) the funding program for next generation world-leading researchers, JSPS, (ii) Development of Systems and Technology for Advanced Measurement and Analysis, Japan Science and Technology Agency (JST) (iii) Adaptable \& Seamless Technology Transfer Program through Target-driven R\&D (A-STEP), JST (iv) Japan Society for the Promotion of Science (JSPS) Grant-in-Aid for Exploratory Research, (v) JSPS Research Fellowships for Young Scientists (vi) the Health Labour Sciences Research Grant, The Ministry of Health Labour and Welfare and (vii) 
Czech MEYS KONTAKT Cz-jp collaboration LH14266 project, Crystal Clear Collaboration in CERN, and EC Marie Curie Initial Training Network LUMINET, no. 316906. In addition, we would like to thank following persons for their support: $\mathrm{Mr}$. Yoshihiro Nakamura in Institute of Multidisciplinary Research for Advanced Materials (IMRAM), and Mr. Hiroshi Uemura, Ms. Keiko Toguchi, Ms. Megumi Sasaki and Ms. Yuka Takeda in IMR, Tohoku University.

\section{References}

[1] M. Nikl, A. Vedda and V.V. Laguta, Single-crystal scintillation materials. In: Springer Handbook of Crystal Growth. Eds: G. Dhanaraj, K. Byrappa, V. Prasad, M. Dudley. Springer Verlag 2010. ISBN: 978-3-540-74182-4. Chapter 50, 1663-1700.

[2] B.D. Milbrath, A.J. Peurrung, M. Bliss, and W.J. Weber, J. Mater. Res., Vol. 23, No. 10 (2008) 2561

[3] M.J. Weber, Nucl. Instr. Meth. Phys. Research A 527 (2004) 9

[4] C. Dujardin, C. Mancini, D. Amans, G. Ledoux, D. Abler, E. Auffray, P. Lecoq, D. Perrodin, A. Petrosyan, K. L. Ovanesyan, J. Appl. Physics 108 (2010) 013510

[5] J. A. Mares, M. Nikl, A. Beitlerova, P. Horodysky, K. Blazek, K. Bartos, C. D’Ambrosio, IEEE Trans. Nucl. Science 59 (2012) 2120

[6] W. Chewpraditkul, L. Swiderski, M. Moszynski, T. Szczesniak, A. Syntfeld-Kazuch, C. Wanarak, P. Limsuwan., phys. stat. sol. (a) 206 (2009) 2599

[7] M. Nikl, A. Yoshikawa, K. Kamada, K. Nejezchleb, C. R. Stanek, J. A. Mares, et. al., Progr. Cryst. Growth Charact. Materials 59 (2013) 47.

[8] N. J. Cherepy, J. D. Kuntz, Z. M. Seeley, S. E. Fisher, O. B. Drury, B. W. Sturm, et. al., in Transparent ceramic scintillators for gamma spectroscopy and radiography: Proc. SPIE on Hard X-Ray, Gamma-Ray, and Neutron Detector Physics XII, 2010, edited by A. Burger, L. A. Franks and R. B. James, vol. 7805.

[9] K. Kamada, T. Yanagida, T. Endo, K. Tsutumi, Y. Fujimoto, A. Fukabori, et. al., Cryst. Growth Des. 11 (2011) 4484.

[10] K. Kamada, T. Yanagida, J. Pejchal, M. Nikl, T. Endo, K. Tsutumi, et. al., J. Phys. D: Appl. Phys. 44 (2011) 505104. 
[11]M. Nikl, H. Ogino, A. Krasnikov, A. Beitlerova, A.Yoshikawa, and T. Fukuda, Phys. Status Solidi A, 202 (2005) R4

[12]H. Ogino, A. Yoshikawa, M. Nikl, K. Kamada, and T. Fukuda, J. Cryst. Growth, 292 (2006) 239

[13]L. Swiderski, M. Moszynski, A. Nassalski, A. Syntfeld-Kazuch, T. Szczesniak, K. Kamada, K. Tsutsumi, Y. Usuki, T. Yanagida, A. Yoshikawa, IEEE Trans. Nucl. Science 56 (2009) 934

[14]I. van V. Khodyuk, Johan T. M. de Haas, and P. Dorenbos, IEEE Trans.Nucl. Science 57 (2010) 1175

[15] K. Kamada, K. Tsutsumi, Y. Usuki, H. Ogino, T. Yanagida, and A.Yoshikawa, IEEE Trans. Nucl. Sci., 55 (2008) 1488

[16] Y. Wu, G. Ren, , Opt. Mater. (2013) doi:10.1016/j.optmat.2013.05.039

[17] V. Babin, M. Nikl, K. Kamada, A. Beitlerova, A. Yoshikawa, J. Phys. D: Applied Phys. 46 (2013) 365303.

[18]A. Yoshikawa, B. M. Epelbaum, K. Hasegawa, et al, J. Cryst. Growth 205 (1999) 305

[19] V.I. Chani, A. Yoshikawa, Y. Kuwano, et al, J. Crystal Growth, 204 (1999) 155

[20] K. Kamada , T. Yanagida, K. Tsutsumi, Y. Usuki, M. Sato, H. Ogino, et. al., IEEE Trans. Nucl. Sci., 56 (2009) 570 
Fig. captions

Fig.1. Example photographs of grown Pr:LGGAG crystals.

Fig.2. Powder $\mathrm{X}$-ray diffraction results of the grown $\operatorname{Pr} 1 \%$ $\mathrm{Lu}_{1} \mathrm{Gd}_{2}\left(\mathrm{Ga}_{\mathrm{x}} \mathrm{Al}_{1-\mathrm{x}}\right)_{5} \mathrm{O}_{12}(\mathrm{x}=1,2,3,4$ and 5) crystals.

Fig.3. The composition distribution of a) $\mathrm{Ga}$ in the as-grown $\operatorname{Pr} 1 \%$ $\mathrm{Lu}_{1} \mathrm{Gd}_{2}\left(\mathrm{Ga}_{\mathrm{x}} \mathrm{Al}_{1-\mathrm{x}}\right)_{5} \mathrm{O}_{12}(\mathrm{x}=1,2,3$ and 4$)$ crystals and b) Pr in the Pr1\%: $\mathrm{Lu}_{2} \mathrm{Gd}_{1} \mathrm{Ga}_{3} \mathrm{Al}_{2} \mathrm{O}_{12}$ crystal, where $\mathrm{C}_{\mathrm{s}}$ is the measured concentration of the cations in the samples and $\mathrm{C}_{0}$ is the initial concentration in the melt.

Fig.4. Absorption spectra of the as-grown Pr:LGGAG crystals, undope LGAGG and Pr:LuAG standard.

Fig.5. RL spectra of the as-grown Pr:LGGAG crystals.

Fig. 6. Pulse height spectra of the Pr:LGAGG crystals excited by a $662 \mathrm{keV}$ gamma-ray source using the PMT at room temperature.

Fig. 7. Scintillation decay curve of the $\operatorname{Pr} 1 \%: \mathrm{Gd}_{3} \mathrm{Ga}_{3} \mathrm{Al}_{2} \mathrm{O}_{12}$ crystal. Scintillation decay is approximated by the sum of two exponentials $I(t)=\Sigma$ $\mathrm{A}_{\mathrm{i}} \exp \left[-\mathrm{t} / \tau_{\mathrm{i}}\right]$, i- 1,2. Ratio (\%) is calculated as $\mathrm{A}_{1} \tau_{1} /\left(\mathrm{A}_{1} \tau_{1}+\mathrm{A}_{2} \tau_{2}\right) \times 100 \%$ for the first component. 
Kamada,et al, Fig. 1

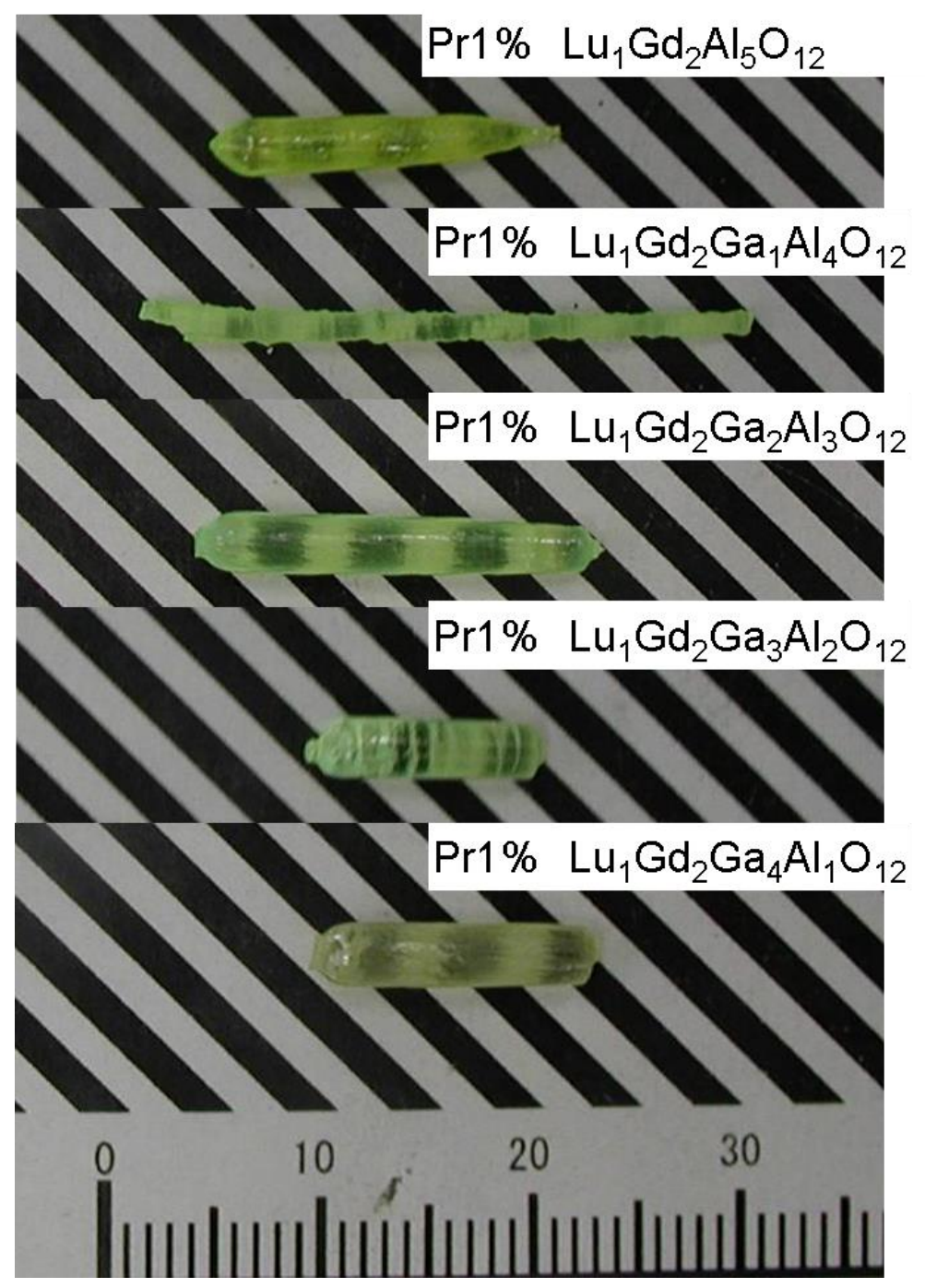


Kamada,et al, Fig. 2

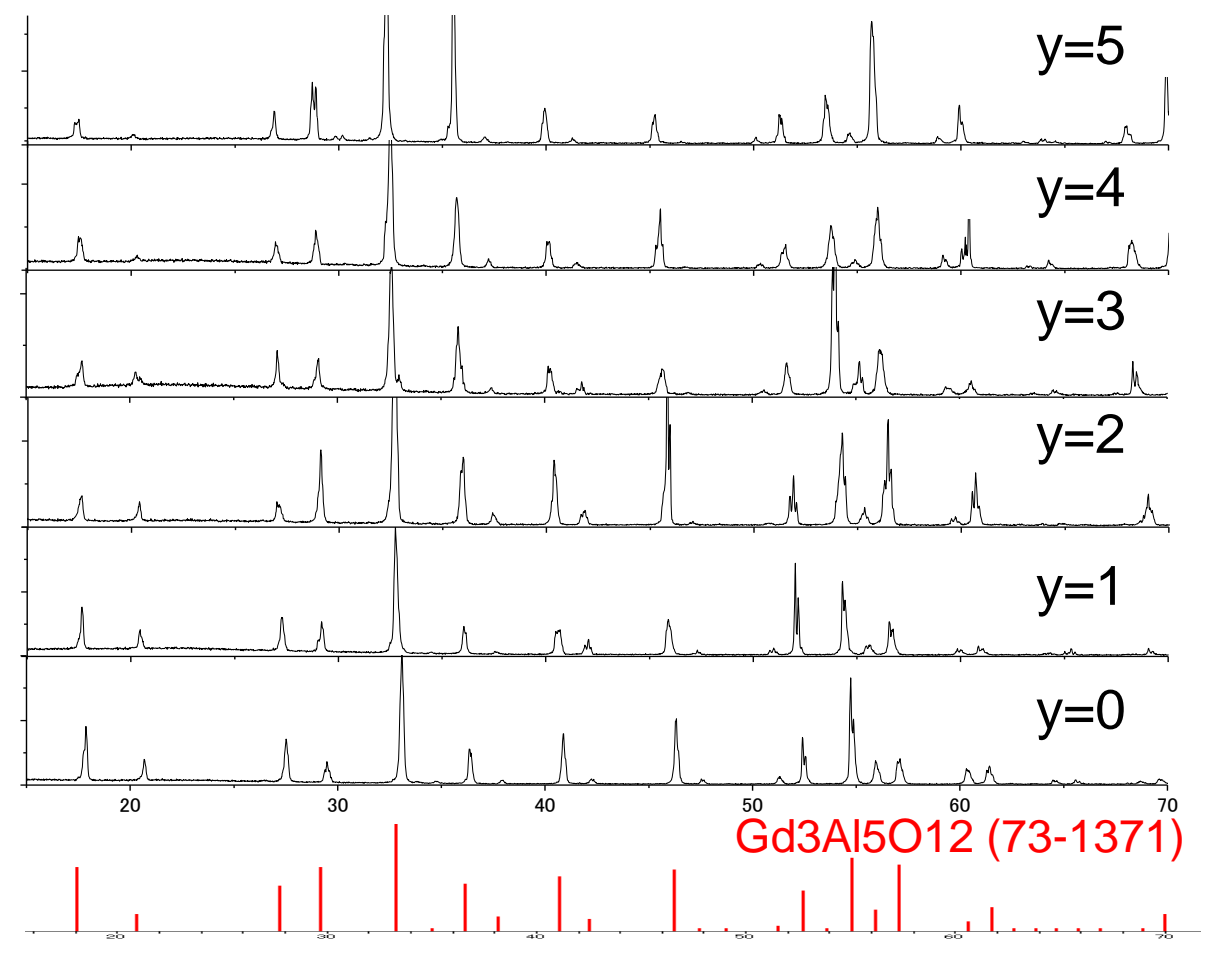


Kamada,et al, Fig. 3

a)

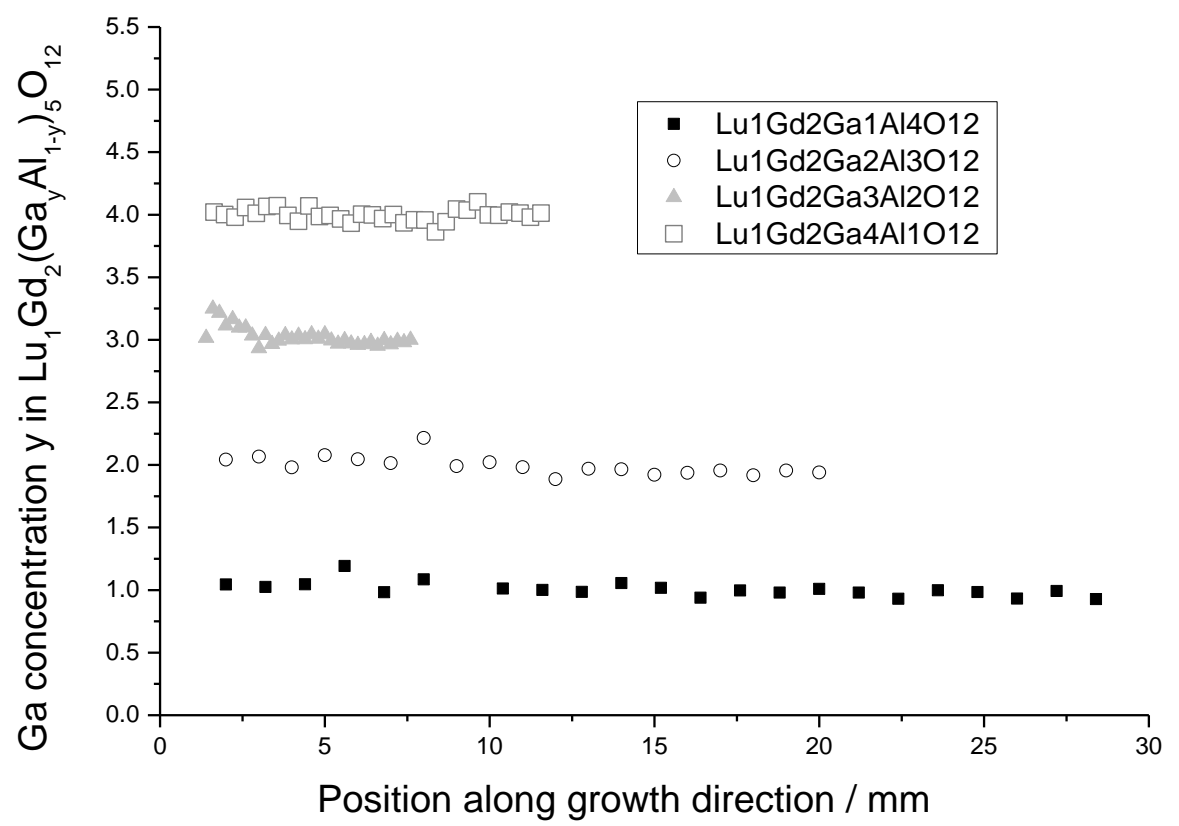

b)

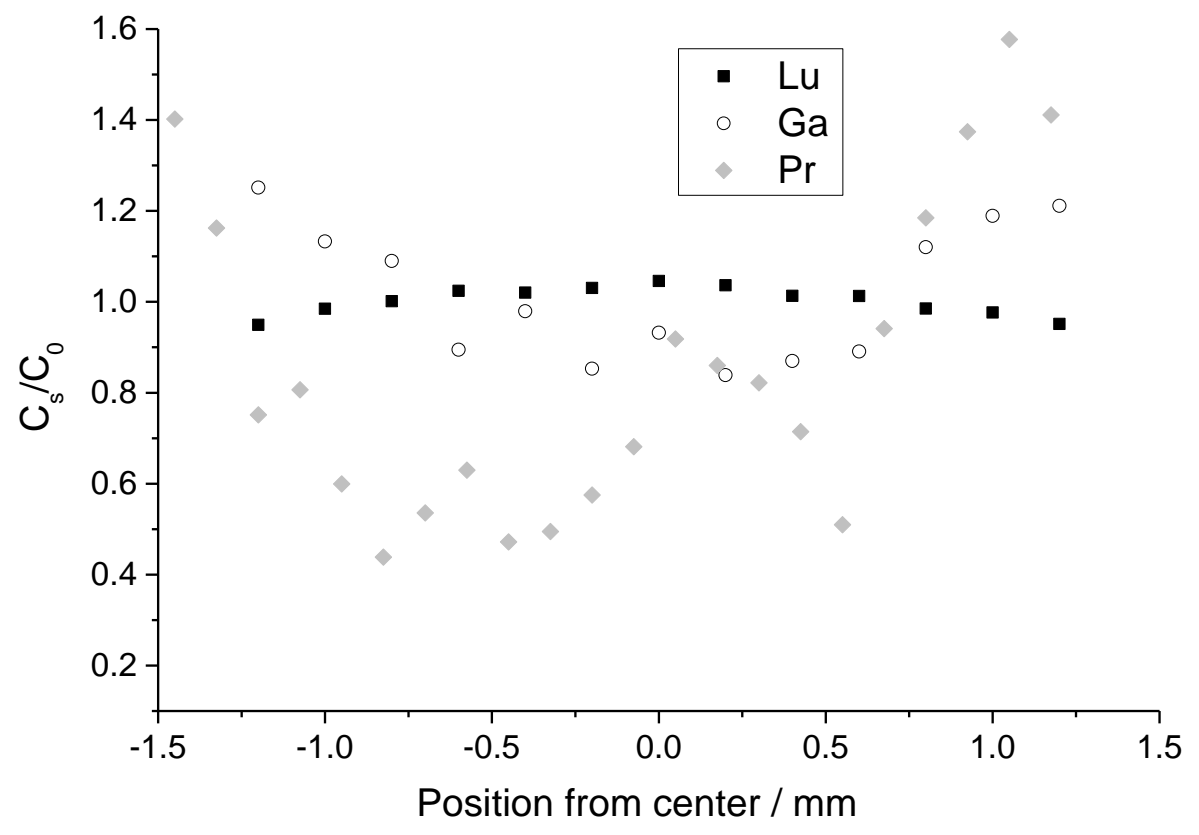


Kamada,et al, Fig. 4

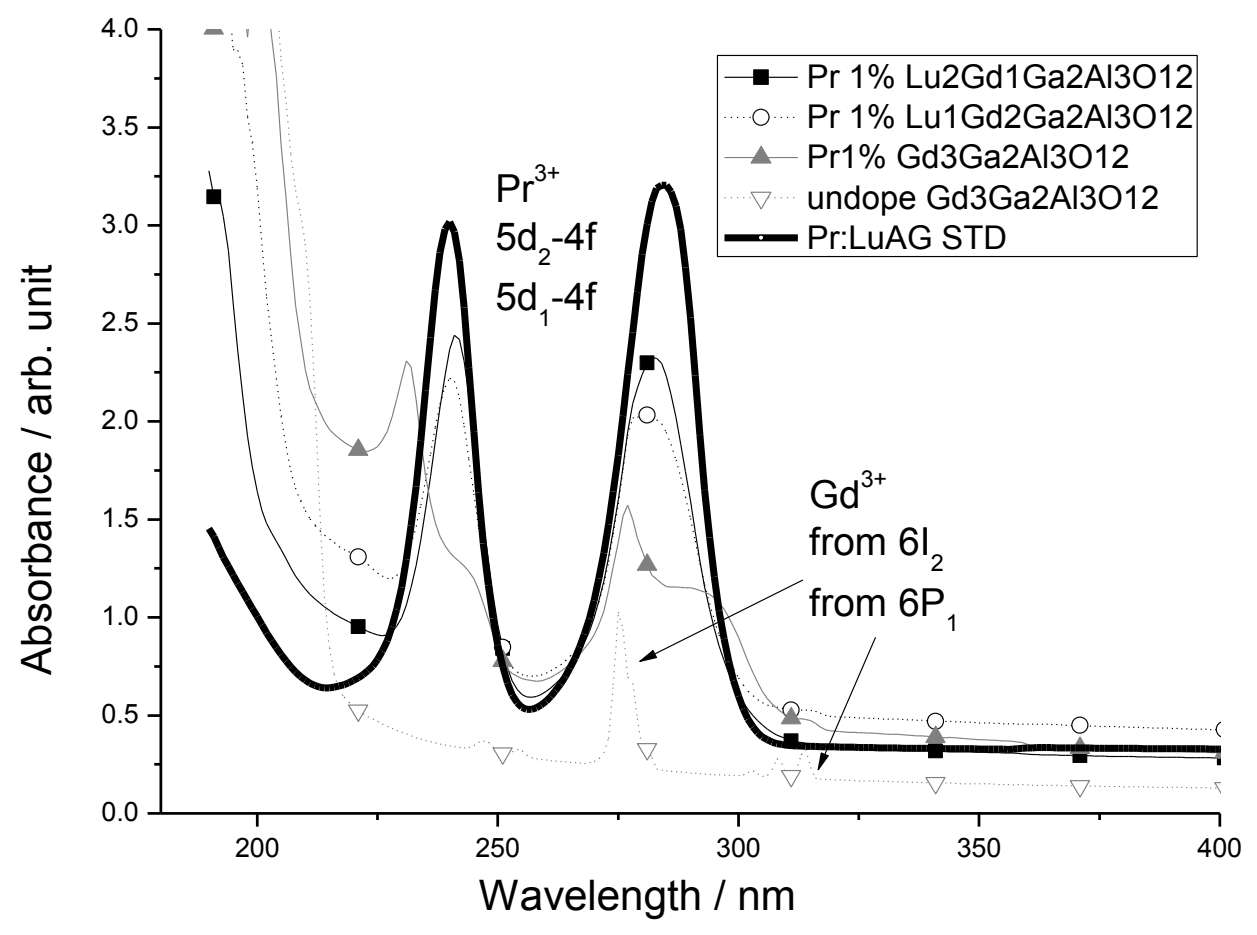


Kamada,et al, Fig. 5

a)

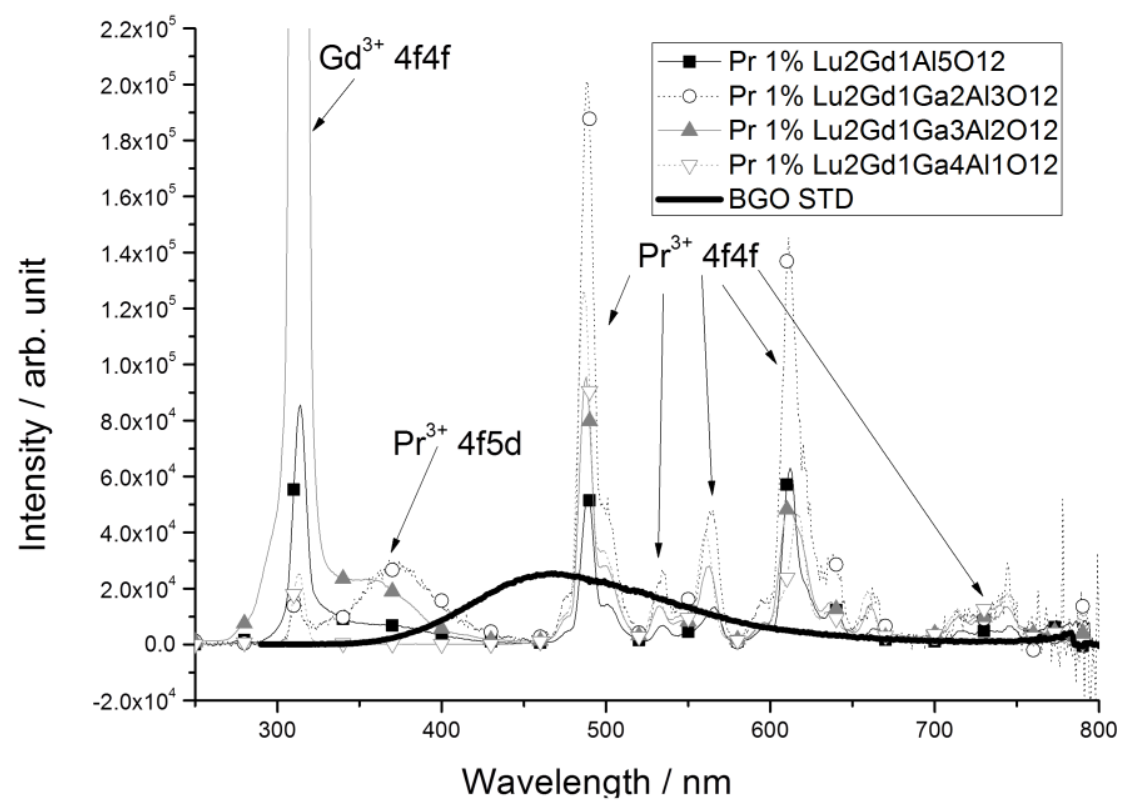

b)

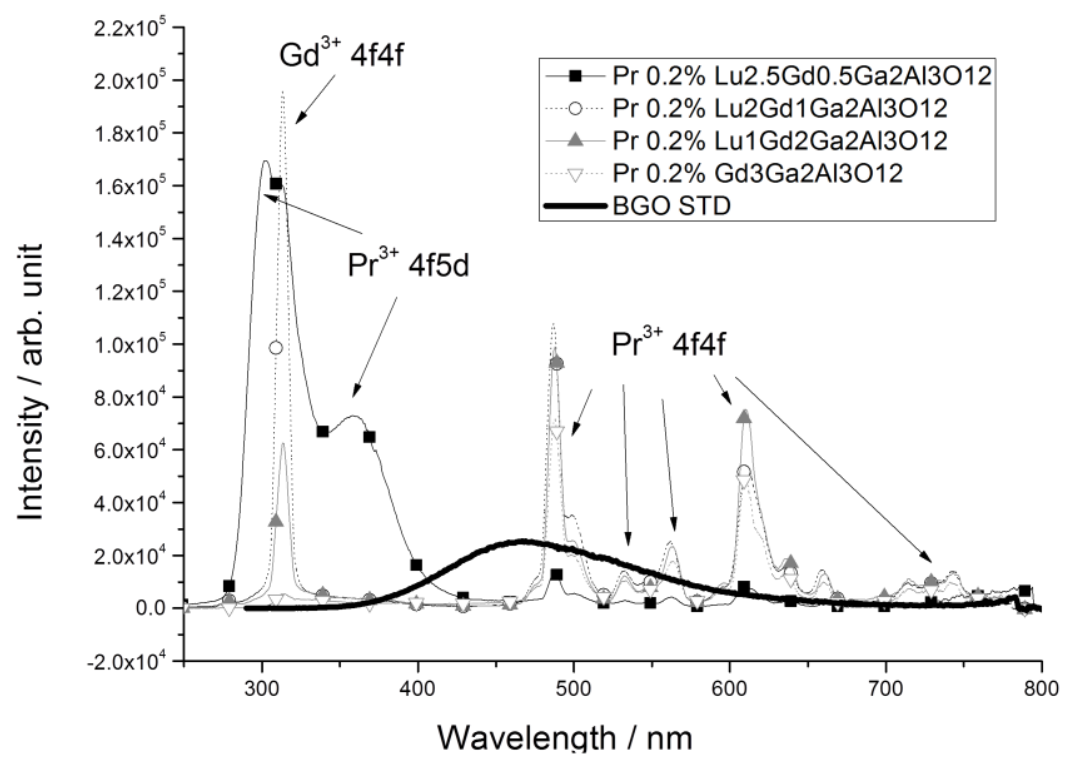


Kamada,et al, Fig. 6

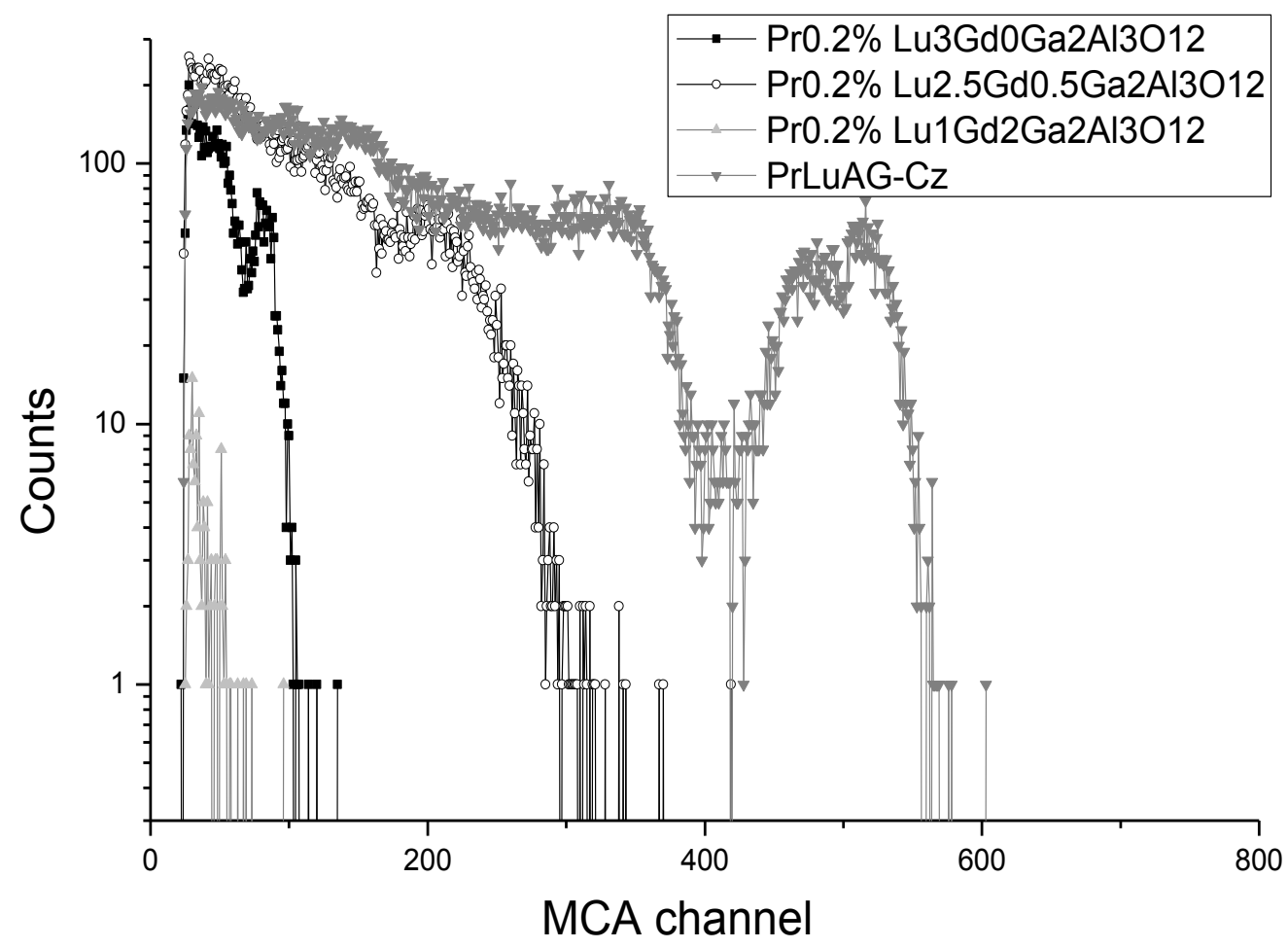


Kamada,et al, Fig. 7

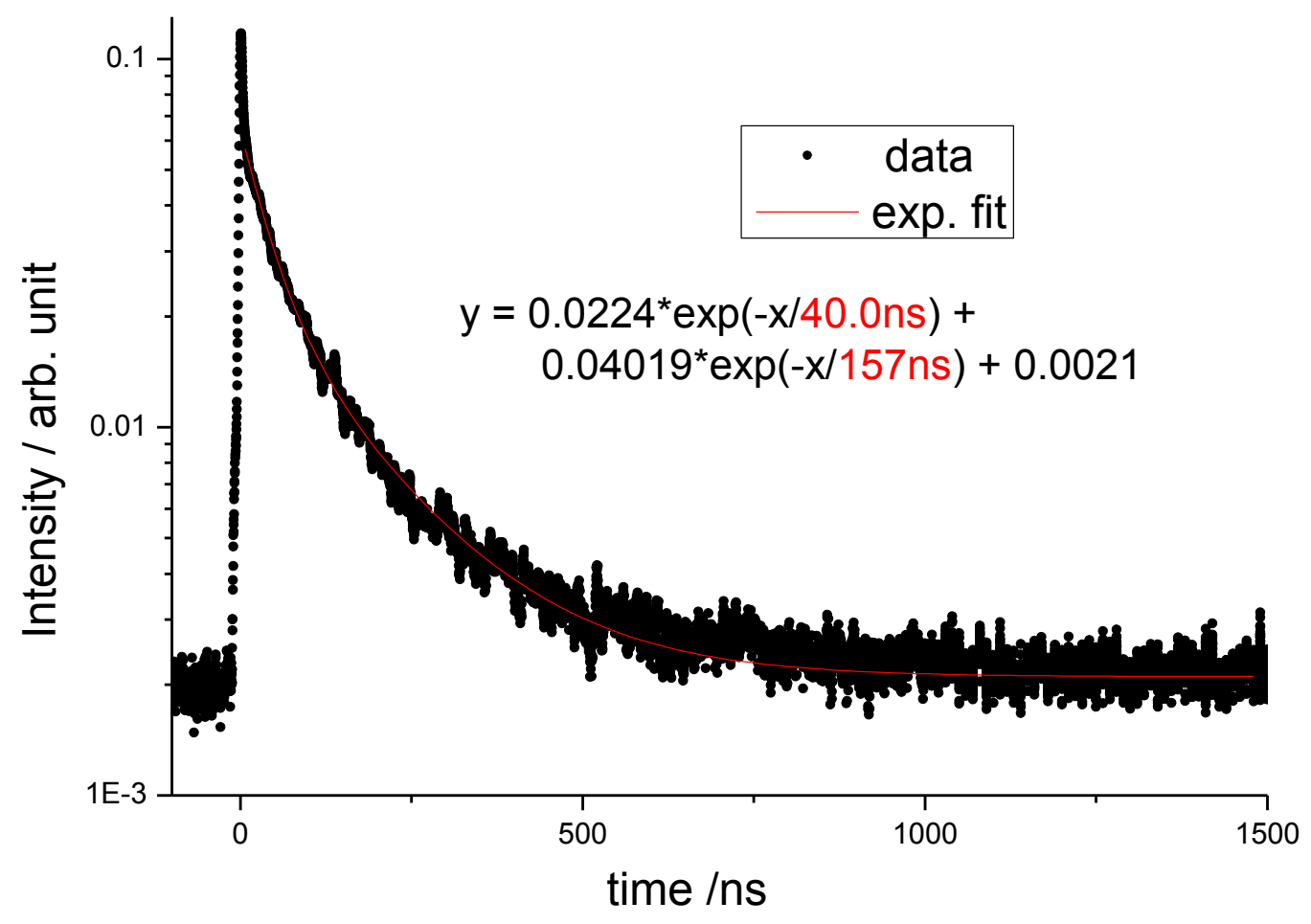

